Original Research Paper

\title{
Cavern Design Philosophy under High Stress Rock Condition a Case Study in Sri Lanka
}

\author{
Bahram Salehi \\ Department of Underground Structure, Saman Kawosh Co, Tehran, Iran
}

\section{Article history}

Received: 13-02-2016

Revised: 11-03-2017

Accepted: 21-03-2017

Email: salehi_emg@yahoo.com

\section{Introduction}

Geomechanic engineers involved in the analysis of support for underground structure are faced with the perplexing problem of deciding upon a suitable design approach. Developments in underground support design have included the use of rock mass classification systems (Barton et al., 1974; Bieniawski, 1974), analytical observational approaches such as the New Austrian Tunnelling Method (Rabcewicz, 1964; 1965), supportinteraction concepts (Ladanyi, 1974) and designs based upon structurally controlled failure mechanisms (Hoek and Brown, 1980; 1977; Croney et al., 1978). Combining these designs approaches with well documented case histories (Cording et al., 1971), means that the designer has access to a valid experience. However, the engineers are still faced with the critical issues of matching the optimum design approach to the

\begin{abstract}
For stabilizing of rock cavern stress condition and orientation, rock properties and cavern geometry have determinant effects. Numerical and analytical study and knowledge about self-support arching can assist to Ther in appropriate understanding of cavern and ground interaction. cavern was not an acceptable design because of high value stress concentration. The elliptical cavern provide best stress distribution. In this research 5 basic concept in a case study cavern design under high stress have a dominant influence in stress redistribution and forming self-support arch, respectively. Very small tangential stress may create radial crack in periphery of the opening. If the rock mass is hard and brittle, rock burst problem may arises in the area of high compressive stress when the rock mass strength is lesser than the imposed compressive stress. If the strength of rock is low compare to the stresses on it. Instability problems may arise after few years of excavation. Uma Oya underground hydro power project cause buckling effect in walls. Result indicates that high value of horizontal stress might cause local tensile spalling. Plastic zones extend to the pillar between to caverns more than 30 to $1.5 \mathrm{~m}$ in the roof. Even after rock calculated in the walls and a tensile zone of $2 \mathrm{~m}$ deep in the roof. thickness of arching are calculated 4.8 to 5.5 for power house and 1.6 to 1.7 $\mathrm{m}$ for transformer cavern, via FEM analysis.
\end{abstract}

Keywords: Cavern, Geometry, Stabilizing, Numerical Analysis, Arching geotechnical conditions and of recommending the suitable method statement.

This paper faces with a specific class of cavern design problem, namely the identification of support design for controlled structurally failure in hard rock under high stress condition. This experimental point of views is discussed in terms of the expedient.

\section{Cavern Design}

Critical design elements are direction and shape of caverns and also width of the rock pillar. The pillar separating the two caverns, which is intersected by several galleries such as tailrace galleries and cable galleries.

A series of analytical/numerical researches were carried out to help understand of various design alternatives. The main concepts considered can be summarized as follows: 
- Cavern orientation

- Optimization of cavern shape

- Distances between caverns

- Stability analysis

- Design of rock reinforcement

\section{Orientation of Caverns}

In high horizontal stress fields, stress induced instability problems are likely to arise in the roof and floor of excavations in the form of spalling or squeezing due to high stress concentrations.

For a rock cover equal to $10 \%$ of the underground structure diameter, the stress concentration in the roof is about seven times the horizontal stress (Hanssen and Myrvang, 1986).

If the rock is bedded, layered or stratified, the effect of high horizontal in situ stresses will be enhanced and will be expressed in the form of buckling and heaving of roof and floor layers, respectively. Slip along layers may also create large inward and horizontal displacements of the Cavern sidewalls. Several case studies showing this phenomenon were described by (Lee, 1978; Franklin and Hungr, 1978), for some Caverns in sedimentary rocks in southern Ontario. To control deformation and stress concentration, the orientation of the main storage cavern with consideration to the geotechnical conditions is highly recommende.

The in situ stress state (magnitude of the horizontal and vertical stresses as well as the orientation of the horizontal stresses) affects the size of openings that can safely be constructed underground and the orientation of the openings that will enhance their stability. Regions subjected to tectonic forces may have maximum stresses that are greatly in excess of the stresses imposed by the vertical load of the rock. Generally, the axis of underground openings should be oriented between 15 and $30^{\circ}$ of the major principal stress (Selmer-Olsen and Broch, 1977).

Orientation of cavern is determined by the orientation of predominant joint sets. All possible weakness zones have to be avoided in or near the cavern alignment. For shallow and intermediate depth, orientation should be along the bisection line of maximum intersection angle between the two predominant joint directions. Close parallelism to the third joint set should be avoided. Character of joint sets, filling material in between the joints, friction properties, joint volume, dip of the joint have also major role for stability.

In case of high anisotropic rock stress condition, underground structure contour are tangential to the plane the major/intermediate principle stress, which primarily bring rock stress problems (Rock bursting and spalling) as shown in Fig. 1.

It is thus important that the opening is oriented so that a minimum of its periphery will have such "touching" of the stress plane.

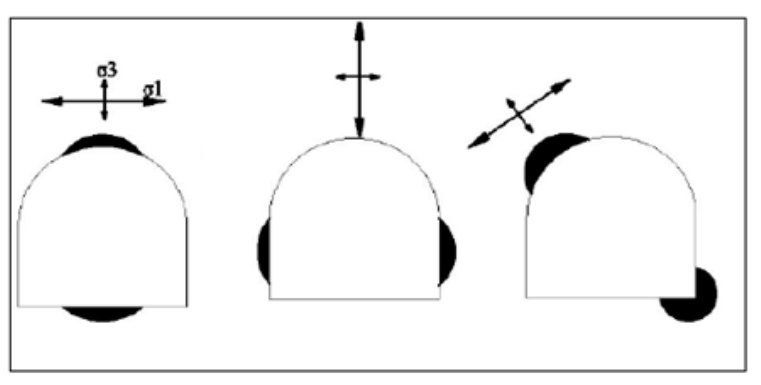

Fig. 1. Direction of major and minor principle stresses determining the nature of rock bursting problem, (Selmer-Olsen and Broch, 1977)

Most stable orientation is obtained when the length axis of the underground opening makes an angle of 15$30^{\circ}$ to the horizontal projection of the major principle stress. Any parallelism with the foliation or other important joint set should be avoided. If the direction of principle stress is close to the direction of bedding of foliation planes in highly anisotropic rocks such as crystalline schist and flagstones then length axis of the opening is oriented with an angle relative to the strike of the foliation plane. Length axis of the opening should be oriented with the maximum angle $5^{\circ}$ with respect to the strike of the foliation plane and $35^{\circ}$ should consider as an absolute minimum (Selmer-Olsen and Broch 1977).

Also it is recommended the long axis of the main caverns should be perpendicular to the most significant discontinuities such as fractures, joints and faults. Obviously, perpendicularity to all negative discontinuities cannot be achieved in an actual situation, so the choice of orientation becomes a best compromise based on experience as to what conditions present the greatest problems to both the cavern stability and air tightness of the operating facility.

If long axis aligned parallel or sub-parallel to maximum horizontal stress, local tensile or spalling fracture should be expected (Cai et al., 2007). In perpendicular maximum stress aligned to cavern axis, shear failure is more possible. It should consider that most rock type's total failure is occurred by shear failure.

Beside, in parallel case controlled deformation will help on stress relaxation and optimum support design can be obtained. Also, special attention must be given to brittle failure of massive rocks struggling spalling local failure.

\section{Geometry Design}

The stability of the cavern will be defined primarily by its shape and only very marginally by the strength of the component material. Thus, it is obligate to design and construct the appropriate shaped structure.

The starting point for the geometry design is the assumption of a standard roof arch. A roof arch with short height increases stability problems and fall-out during blasting. Increasing the roof arch height will improve global stability but also increase the excavation cost. 
Cavern walls are normally vertical. This suits the method of excavation and yields little unusable space. Wall stability is affected by wall height, the in-situ stresses and the orientation and properties of principal joint set. The flat wall precludes any substantial arching action and high walls propend to instability.

Principal joints and stratifications can affect wall stability and dominate the chosen wall height.

A study on three different cavern shapes in same geotechnical condition was investigated by (Hoek, 2006). These cavern shapes were:

a. A mushroom shaped structure with a concrete arch roof

b. A traditional horseshoe shaped cavern having vertical sidewalls

c. An elliptical cavern which is designed for optimal stress distribution in the rock mass surrounding it

The purpose of illustrating the mushroom shaped cavern was for referencing purposes since the behavior of the cavern had been well documented. The horseshoe shaped cross section was the preferred choice in terms of easy construction. The elliptical cross section was also analyzed. The typical results of analyses of these three cavern shapes are presented in Fig. 2-4.

The comparative studies illustrated in Fig. 2-4, showed that the mushroom shaped cavern was not an acceptable design because of high value stress concentration. The best stress distribution was given by the elliptical cavern (Hoek, 2006).

\section{Distance between Caverns}

The width of pillars depends primarily on the geotechnical condition, the discontinuity orientations, the cavern spans and heights and any openings formed in the pillars (Berthelsen, 1992). In-situ stresses can also affect pillar widths, especially for deep caverns. Pillar widths are normally equal to between half and the full cavern height or span, whichever is the greater.

At the preliminary planning stage pillar widths should be conservative. As planning progresses on the basis of improved geological data, narrower pillars may be considered. Pillar widths are normally determined on the basis of designer experiences and analytical analysis. Estimates of acceptable pillar width can be made on the basis of assuming kinematic ally possible sliding on unfavorable joints and calculating the factors of safety.

Estimates of principal stresses and joint shear strengths in the pillar are required for this type of analysis. Pillar widths designed to the theoretically defendable limit will commonly also give rise to additional excavation and support problems. However, at some sites narrow or slender pillars may be required because of limitation in construction, faults and other restrictions and the additional complications and costs will have to be accepted.

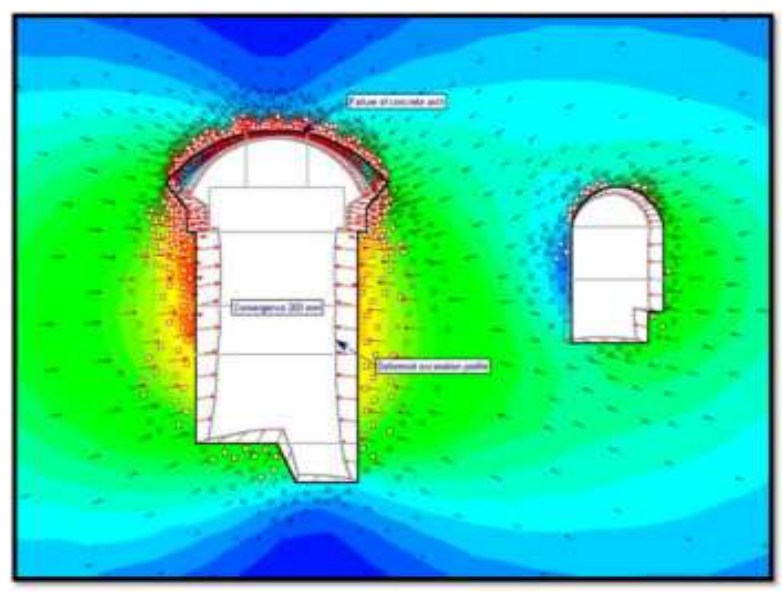

Fig. 2. Deformation and failure of the rock mass surrounding a mushroom shaped cavern with. Failure of the arch means that this design is not acceptable (Hoek, 2006)

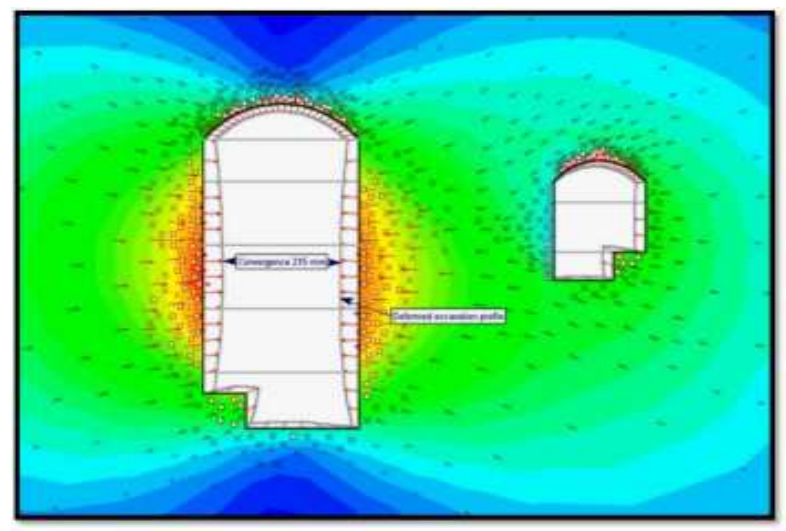

Fig. 3. Deformation and failure of the rock mass around an unsupported horseshoe shaped cavern. Failure of the rock mass in the roof and sidewalls is such that extensive support will be required (Hoek, 2006)

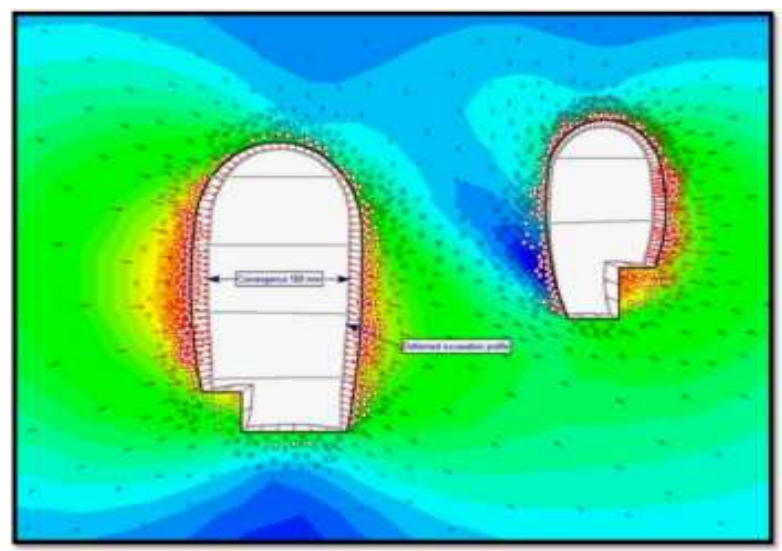

Fig. 4. Deformation and failure of the rock mass surrounding an unsupported elliptical cavern. Failure of the rock mass in the roof and sidewalls is such that extensive support will be required, although less than for the horseshoe shaped cavern (Hoek, 2006) 
The analyses presented in Fig. 3 indicate the usual pattern of deformation in which case the smaller transformer gallery will tend to bring itself towards the larger machine hall.

This is not cause of concern when the pillar between two caverns is large enough but on the other hand, if the pillar is extremely small, the pillar can be overstressed. In this regards a research was performed in that case the width of the pillar in between the transformer gallery and the machine hall was differing.

The outcome of this research showed that the optimum pillar width would be obtained when the distance between the two caverns is almost equal to the height of the larger hall. The results are usually used while designing the caverns in weak type of rock masses. It hard rock's the pillar width can be less if calculation and modeling result confirm it.

The stress on pillar depends on the ratio of the pillar size and room size. In case of square pillar with identical size, the average vertical stress in pillar is defined by:

$\sigma_{p}=\gamma H\left(\frac{W_{p}+W_{o}}{W_{p}}\right)^{2}$

Where:

$\gamma=$ Unit weight of the overlying rock mass

$H=$ Depth of the pillar below surface

$W_{p}=$ Width of the pillar

$W_{o}=$ Width of the opening or road way

\section{Stability Analysis}

In this chapter, items contributing to the forming of a natural rock roof arch and factors required to reinforce the roof are investigated.

\section{Rock Behavior}

The existing rock mass failure criteria are stress dependent and often include one or several parameters that describe the rock mass properties. Because the collapse of the rock microstructure is a complex process, it is not clear which is the correct parameter, or combination of parameters, to use in a failure criterion. As a result, the most widely used failure criteria are empirical criteria based on the stress components, especially the Mohr-Coulomb and Hoek-Brown failure criteria. Chosen proper failure criteria will help to interpret of analysis result.

The suitability of two failure criteria for particular type of rock mass is shown in Fig. 5. If the structure being large compare to the block size (Heavily jointed) then the rock mass strength have to be determined by using Hoek-Brown failure criterion. If the discontinuity spacing is larger (Either one or two joint sets) in comparison to structure dimension then Mohr-Coulomb failure criterion can be used for the stability analysis (Panthi, 2006).

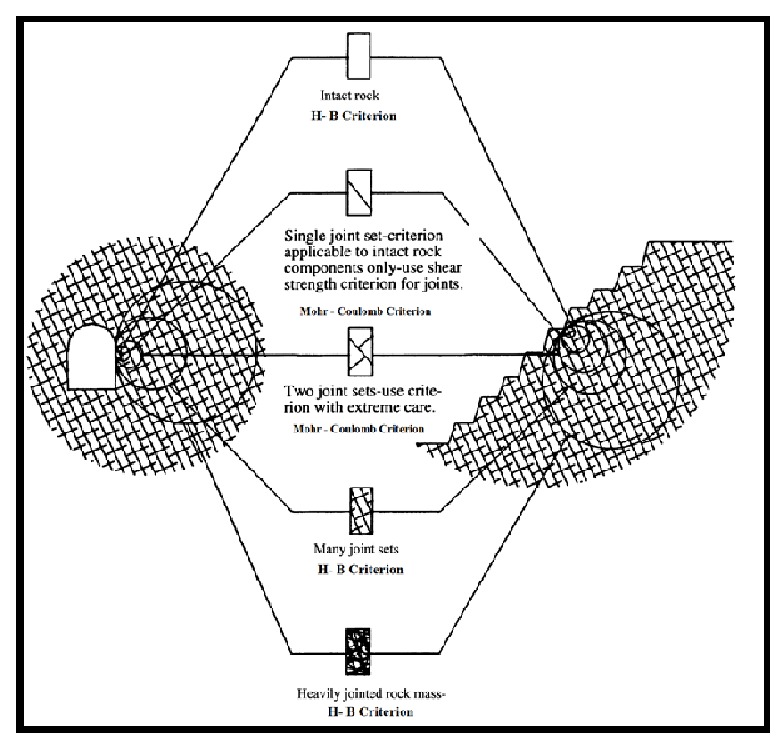

Fig. 5. Failure criteria for different rock mass conditions (Hoek et al., 2000)

Because of discontinuity in the rock mass, it cannot resist high tensile stress. Very small tangential stress may create radial crack in periphery of the opening. Generally, minor cracks does not create problem of stability. In case of high-pressure underground structure, it is more important that secondary jointing and opening of existing joints may create the risk of water leakages out of the cavern.

In the contour of the underground opening, normally there are diametrically opposite area of tangential stress concentration. Stability problems normally occur in the high stress concentration area but very low tangential stress may also create the problems.

If the rock mass is hard and brittle, rock burst problem may arises in the area of high compressive stress when the rock mass strength is lesser than the imposed compressive stress (Table 1).

If the fracturing is accompanied by strong noises then it is called spalling. Main cause of rock spalling is asymmetric shape of the tunnel/cavern profile. Location of spalling/popping out of rock indicates the direction of major principle stress. If major principal is parallel to the cavern axis, so spalling should be expected.

This problem generally occurs just after the excavation takes place, if the strength of rock is low compare to the stresses on it.

Instability problems may arise after few years of excavation. (Due to reduction on strength of rock mass cause by water pressure, creep etc).

In each case local and global stability should concern. It is recommended to use experimental method (such as RMR and Q) for basic stability and support design. Author does not share this opinion in high stress condition. 
Table 1. Prediction of stress related problems according to the Q-system (Grimstad and Barton, 1993)

\begin{tabular}{lcc}
\hline Consequence of stresses & $\sigma_{\mathrm{c}} / \sigma_{1}$ & $\sigma_{\mathrm{c}} / \sigma_{\ominus}$ \\
\hline 1) In competent, massive, hard rock & & $0.5-0.65$ \\
Moderate Spalling after $>1 \mathrm{~h}$ & $5-3$ & $0.65-1$ \\
Spalling and rock burst after a few minutes & $3-2$ & $>1$ \\
Heavy rock burst (strain burst) and immediate dynamic deformation & $<2$ & $1-5$ \\
2) In squeezing rock & & $>5$ \\
Mild squeezing & & \\
Heavy squeezing & & \\
\hline
\end{tabular}

Rock mass classification is a method for monitoring, recording and comparing the predicted and actual rock mass conditions. It gives quantitative measurement of quality of rock mass. These rock mass classification systems should only be used for preliminary/planning purpose and not for the final cavern support.

\section{Numerical and Analytical Analysis}

Rock mass in modeling is discrete into a large number of individual elements and are analyzed for rock stresses and deformation. FEM/DEM in global stability analysis can provide rational information. For rock masses with a limited number of discontinuities, the numerical methods and the analytical method must be used.

The Analytical methods are based upon the limit equilibrium of a failure mechanism that consists of a wedge and the overlying prism. The size and shape of wedges formed in the rock mass surrounding a underground structure excavation depend upon geometry and orientation of the cavern and also upon the orientation of the joint sets.

Simple stability analyses of problematic areas using limit equilibrium methods are therefore often used to supplement the support design given by the rock classification systems.

Key block analyses also must be used to determine which blocks in a cavern roof or walls control the stability. Securing these key blocks will ensure overall stability. The analyses may be used to predict the likely location and appearance of key blocks using statistical joint data or joint maps taken from excavations when specific key blocks can be identified.

The wedge bearing capacity depends on amount the shear resistance offered by ground and support force given by the bolts. The stability is improved considerably by the shear resistance of both the lateral, vertical slip surfaces of the wedge. On the other hand the frictional role of shear stress is affected by respective normal stress (i.e., on the horizontal stress $\sigma \mathrm{x}$ ), which cannot be conclude from the equilibrium conditions.

To perfect solution to the limitations of empirical and analytical tools, is to use numerical methods. For example the Finite Element (FE) and Finite Difference (FD) methods, these are capable of modeling full complexity of a cavern explicitly.

Numerical models are used to extrapolate and occasionally to check, the empirical methods and designs. Such modelling can increase confidence in a particular design and in interpreting instrumentation results. This methods offer the ability to model explicitly complex structures, including adjacent structures, different geological strata, complex constitutive behavior, transient and dynamic loading and construction sequences. This provides an unparalleled capability for simulating ground-support interaction. But care must be given for choosing appropriate method. The numerical methods are sensitive to mesh size/type and also solver which software use. So it should employ wisely.

\section{Design of Rock Reinforcement}

The goal of any ground support system should be to help the rock mass to support itself and not to support the dead weight of loose rock. In this regards shotcrete and rock bolts are most common used elements.

\section{Rock Bolt Effect}

The design of rock bolt is concerned with length to space ratio which is based on limit analysis of a reinforced rock arch. The derivation is obtained by arch thrust line with concerning of in-situ horizontal stress as well as the thickness of the arch ring.

The bolt length should be long sufficiently to contribute the maximum shear stress which may develop and to crosscritical joints having sufficient length of anchorage.

The shear failure in jointed rock and shear failure due to incomplete arch forming is common. In this case, reinforcement of the rock roof arch is imperative. The use of fully grouted rock bolts is effective to prevent the sliding, opening and offer confining pressure fast than the point anchored rock bolt/cable that cannot offer shear resistance before significant shearing has already taken place.

In rock bolt design must attend to choose accurate type. The tensioned cable may increase wall displacements due to the mechanism of the coupling of roof deformation with wall deformation in the cavern with a high wall.

The cables create stresses irregularly in the arch and also stress concentration at the arch ribs which is due to availability of the area between cables that will force high tensional forces to the rock blocks surrounding. Adding to it, the cables which are tensioned and also passing in the arch, will apply pressure additionally on internal support on the roof surface which can form uprising forces to the rotated rock blocks. 


\section{Shotcrete Effect}

The effect of shotcrete liner change with the loading environment (stress Vs. structurally controlled) and throw other factors: The magnitude and direction of loads. Shotcrete helps the ground support system accomplish this objective by preventing the rock mass from traveling and loosening, thereby allowing it to maintain its inherent strength. In blocky ground sprayed liner support can be very beneficial.

The shotcrete-rock interaction however, is very complex and its performance is influenced by a number of important factors:

- The roughness of the opening

- The mechanical properties of the rock

- The rock stress

- The disturbed zone around the opening

- The discontinuities

- The rock bolts

- The interface between shotcrete and rock

- The arching effect

The influence of all these factors is almost impossible to analyses using analytical or experimental models due to the complexity of the rock-shotcrete interaction. Here, arching theory is considered most.

Shotcrete can also support the rock through the structural arch support mechanism. Shotcrete prevents the differential movement of crushed rock thereby causing a generally even inward displacement of the rock. As the rock moves inwards the length of the excavation contour decreases resulting in compressive forces acting on the shotcrete-rock composite. The early strength of the liner plays an important role if the shotcrete is to achieve a structural arch support mechanism.

The arch would be stressed by pure compression and that the stability of the excavation relies on the strength of the arch. However shotcrete only prevents the loosening of the rock thereby transforming the surrounding rock into a self-supporting arch.

\section{Case Study}

The underground hydropower Uma Oya project is located in the southern part of the central hills in Sri Lanka. The detail of the powerhouse cavern is as follow, the internal length of $70 \mathrm{~m}$, having of $18 \mathrm{~m}$ width and height which can vary up to $32 \mathrm{~m}$. The side walls are curved slightly inwards to achieve proper stress distribution in the surrounding rock. The shorter and smaller transformer cavern has vertical side walls with $30 \mathrm{~m}$ length, $14 \mathrm{~m}$ width and 13 high (Fig. 6). This project is under construction and will finish in end of 2016.

\section{Geology and Rock Properties of Caverns}

Charnokitic gneiss, clac silicate gneiss, Garnet gneiss and few quarts rich gneiss rock types present in caverns. The ground water table is about $8 \sim 86 \mathrm{~m}$ lower than ground surface. About 3 systematic joint set and a foliation was observed during the investigation. Situation of the transformer cavern is unfair relatively power cavern. The major joint sets are sheared and strike parallel with the cavern axis. Summary of discontinuities has presented in Table 2 and 3. This data has been used in equilibrium limits methods analysis.

Because of $680 \mathrm{~m}$ over burden, high principal stress adversely affects the overall conditions. Based on primary stress measurements using the hydraulic fracture tests in vertical boreholes, it was found that the maximum horizontal stress, vertical stress and minimum horizontal stress are 20,18.5 and 9 Mpa respectively (The coefficient of lateral earth pressure, $\mathrm{K} 0 \approx 1.1$ ).

Also, principal stress direction are, $\theta$ or strike of fracture plane (north over east): $67^{\circ}, \beta$ or dip direction of fracture plane: $136^{\circ}$ and $\alpha$ or dip of fracture plane with respect to horizontal: $77^{\circ}$.

The average and pessimistic values are given by the geologist engineers were transformed to executable design assumptions through the Global Strength Index (GSI). Because of high over burden and infrequent geotechnical data, the Hoek-Brown and Mohr-Coulomb criterion both were attended as principal for estimating the properties of rock mass.

Following input parameters have been used:

Rock sample scale: Linear elastic:

- $\quad \mathrm{E}=21 \mathrm{GPa} ;$ Stiffness

- $v=0.25$; Poisson's ratio

- $\gamma=28 \mathrm{kN} / \mathrm{m} 3$; Unit weight

Rock mass scale: Hoek-Brown:

- $\quad \mathrm{E}=16 \mathrm{GPa} ;$ Stiffness

- $v=0.25$; Poisson's ratio

- $\gamma=28 \mathrm{kN} / \mathrm{m} 3$; Unit weight

- $\mathrm{UCS}=57 \mathrm{MPa}$; Uniaxial compressive strength

- $\mathrm{GSI}=77$; Geological strength index

- $\mathrm{mi}=12$; Curvature coefficient

- $\mathrm{D}=0.1$; Disturbance factor

Rock mass scale: Mohr-Coulomb:

- $\quad \mathrm{E}=16 \mathrm{GPa} ;$ Stiffness

- $v=0.25$; Poisson's ratio

- $\gamma=28 \mathrm{kN} / \mathrm{m} 3$; Unit weight

- $v=0.25$; Poisson's ratio

- $\gamma=28 \mathrm{kN} / \mathrm{m} 3$; Unit weight

- $\mathrm{f}=43^{\circ}$; Friction angle

- $\mathrm{c}=3.8 \mathrm{MPa} ;$ Cohesion

- $\mathrm{t}=0 \mathrm{MPa}$; Tensile strength 


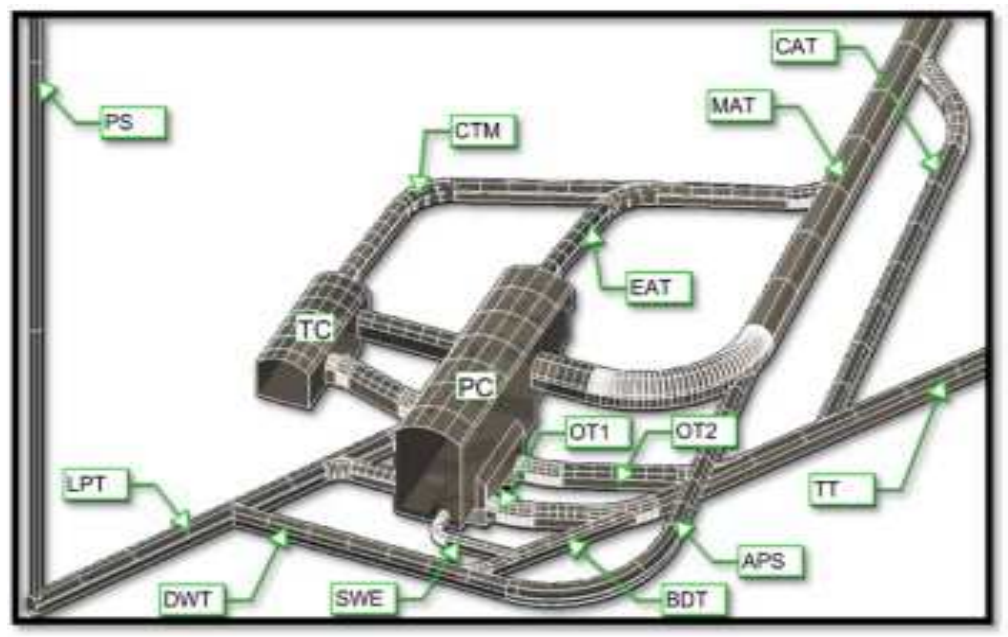

Fig. 6. Umo Oya hydropower project

Table 2. Summary of the discontinuities in power cavern

\begin{tabular}{lllllll}
\hline Chain: & Location & $\begin{array}{l}\text { Main joints } \\
\text { (Dip/Dip direction) }\end{array}$ & $\begin{array}{l}\text { Spacing } \\
\mathrm{cm}\end{array}$ & $\begin{array}{l}\text { Aperture } \\
\mathrm{mm}\end{array}$ & $\begin{array}{l}\text { Persis. } \\
\mathrm{M}\end{array}$ & Remarks \\
\hline $0-10$ & Crown & Foliation 27/271 & $10-40$ & $0-0.1$ & $5-20$ & slickenside, Planer, Mica filled \\
$0-10$ & Wall & J1.87/096 & $5-0$ & 0.1 & $2-3$ & $0-1$ mm clay coating presents \\
$0-10$ & Full section & J2.84/356 & $7-30$ & $0-0.1$ & $1-3$ & Rough, undulated \\
$10-25$ & Wall & $87 / 096$ & $10-20$ & 0.1 & $2-3$ & $0-1$ mm clay coating presents \\
$10-25$ & Wall & Foliation 27/271 & $10-40$ & $0-0.1$ & $5-20$ & slickenside, Planer, Mica filled \\
$25-69.85$ & Full section & J1, J2 and Foliation & $20-30$ & 0 & $0.5-2$ & Rough, undulate, Tight joints \\
\hline
\end{tabular}

Table 3. Summary of the discontinuities in Transformer cavern

\begin{tabular}{|c|c|c|c|c|c|c|}
\hline & Chainage & $\begin{array}{l}\text { Joints } \\
\text { (Dip/Dip direction) }\end{array}$ & $\begin{array}{l}\text { Spacing } \\
\mathrm{cm}\end{array}$ & $\begin{array}{l}\text { Aperture } \\
\mathrm{mm}\end{array}$ & $\begin{array}{l}\text { Persistence } \\
\mathrm{m}\end{array}$ & Remarks \\
\hline \multirow[t]{4}{*}{1} & $0-20 \mathrm{~m}$ & $72 / 015$ & 15 & 0.1 & 8-Mar & Closely spaced, \\
\hline & & 78/098 & 30-May & $0-1$ & 5-Mar & Sheared joints \\
\hline & & $27 / 271$ & 60 & 0 & 5 & Very unstable wall \\
\hline & & $88 / 050$ & 3,5 & 0.1 & 5 & \\
\hline \multirow[t]{2}{*}{2} & $20-30 \mathrm{~m}$ & $87 / 350$ & 5 & 0.1 & $>20$ & Medium spacing \\
\hline & & 78/096 & 46 & 0.1 & $>3$ & Fair crown \\
\hline \multirow[t]{3}{*}{3} & $30-40 \mathrm{~m}$ & $84 / 188$ & 20 & 0 & $>10$ & Closely spaced, \\
\hline & & $72 / 096$ & 17 & 0 & 5 & Sheared joints \\
\hline & & $87 / 356$ & 30 & 0 & 3 & \\
\hline
\end{tabular}

\section{Design Process}

The Uma Oya power cavern was designed by traditional methods involving the use of shotcrete and rock bolt arch for supporting the cavern roof. Because of high over burden and high stresses condition, the shape of cavern play very important role in stress distribution and optimize support system.

According to numerical analysis results, elliptical cavern showed best stress distribution but it was also specified that the amount of support which is required to stabilize this and the horseshoe shaped cavern would not be different significantly. Therefore the final chosen cross section was conventional horseshoe. It was also contemplate that it will make the construction cost more effective and construction procedure simple for overall underground complex, comparing to an elliptical cavern. The cravens' axis oriented sub-parallel to the maximum stress direction $\left(30^{\circ}\right)$.

Discontinuum and continuum aspects were treated in separate computational models. The FEM software was used to determine extension of failure zones in different sort of rock properties and lateral pressure coefficients in a 2D plane strain model.

The caverns are situated almost $680 \mathrm{~m}$ deep beneath the surface of ground. To provide a FE mesh with complete overburden height would be inefficient, computationally.

Top of the model is fixed and for filed stress according to overburden and lateral stress ratio, has been used the constant field stress to define stress field. Constant field stress is typically used for excavations which are relatively deep. The selection of computational boundary conditions 
are depending upon ability to neglect secondary influences at the boundaries. The followings are set if conditions given by FEM model.

Top face is fixed as prescribed, the side surfaces are having roller boundaries (horizontal fixities) and the bottom face of the FE model is fixed horizontally and vertically.

The analysis performed in 2D analyses and the rock mass was modelled with 3-noded triangular elements. Also isotropic and homogenous behavior was concerned during basic design, the following constitutive models were applied to simulate more realistic rock mass behavior:

- Mohr-Coulomb failure criterion with/without strain softening considering Isotropic behavior

- Hoek-Brown failure criterion with/without strain softening considering Isotropic behavior

It is necessary to mentioned, in both constitutive law, elastic analysis also considered for defining force and stress condition around the caverns (Fig. 7 and 8). In next step sequential and elastic-plastic analysis also has been applied.

In the primary design stage distance of two caverns has been decided $31 \mathrm{~m}$. According to FEM modeling maximum stress on crown is $48 \mathrm{MPa}$ via Mohr-Coulomb and $45 \mathrm{Mpa}$ in Hoek-Brown criteria.

The maximum stress (according to Equation 1) on pillar computed $49 \mathrm{Mpa}$. Also, according to Hoek and Brown (1997), the global strength of pillar is assessed 20 to $35 \mathrm{Mpa}$.

Because of high over burden and variant of data during investigations, two failure criteria has used.

In the design procedure FEM and equilibrium limits methods have been used. The size and mobility of key blocks was assessed in 3D e.g., with the software Unwedge. For all wedge, the limit equilibrium at failure is evaluated. This implies the rock support to be considered at failure stage as well. Intersection between joint sets and foliation causes some unstable blocks in roof and south wall. Wight of some block pass 3000 tons in final stage of excavation (Fig. 9). before including the support system global safety factor in left wall of power house were less than 0.5 , but after applying $6 \mathrm{~m}$ rock bolts, its improve to 6.4 .

The foreseen rock support measures are systematic rock-bolting and fiber reinforced shotcrete (for ductility). Anchor length and pattern as well as the shotcrete layer thickness can be adapted following the encountered conditions, provided that the rock support work is carried out while the rock surface is still reachable.

The rock support is included to the Finite Element Calculations according to its appearance within the excavation steps. This allows gathering information about the behavior of the rock support interacting with the excavation of the caverns.

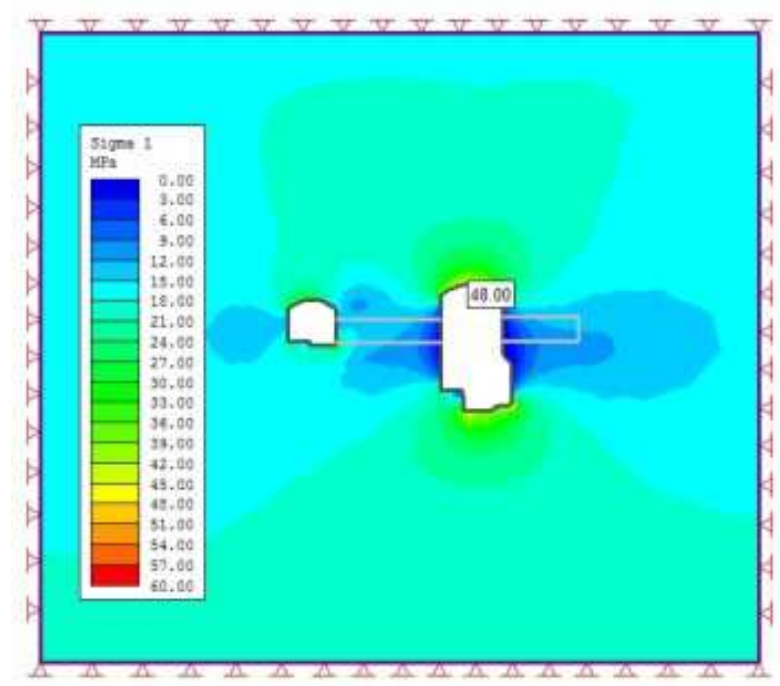

Fig. 7. Major principal stress on Rock-Mohr-Coulomb criteria

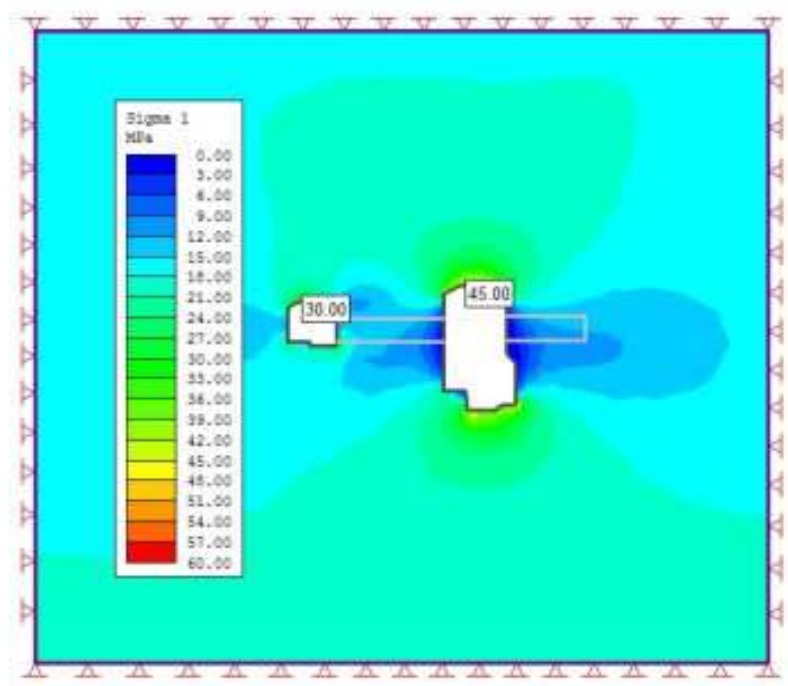

Fig. 8. Major principal stress on Rock-Hoek-Brown criteria

For support system Grade 830 rock bolts and steel fiber shotcrete $(30 \mathrm{Mpa})$ has been considered. In powerhouse cavern rock bolts include $36 \mathrm{~mm}$ in 6 and 8 $\mathrm{m}$ length (pattern $1.5 \times 1.5 \mathrm{~m}$ ). In Transformer cavern 32 $\mathrm{mm}$ rock bolts with 6 and $4 \mathrm{~m}$ length was chosen.

Because of early acting of shotcreret under stress, stiffness chosen for young shotcrete, $E=10 \mathrm{Gpa}$. Details for shotcrete thickness are mentioned in Table 4.

The sequence of excavation and rock support details has been shown in Fig. 10 and 11 .

As additional measures, when unfavorable joint traces are recognized during excavation, pre-stressed tendon anchors are considered for retaining any encountered large blocks with a high apex exceeding the rock-bolt length. 


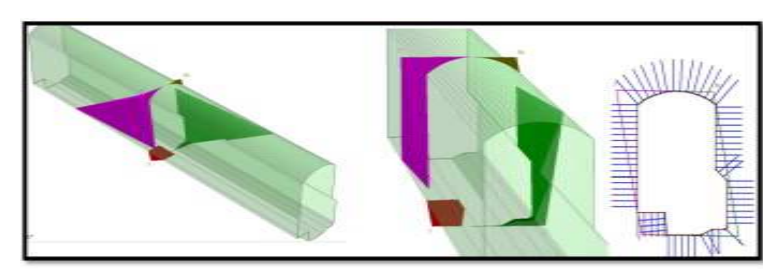

Fig. 9. Formed wedges in roof and walls

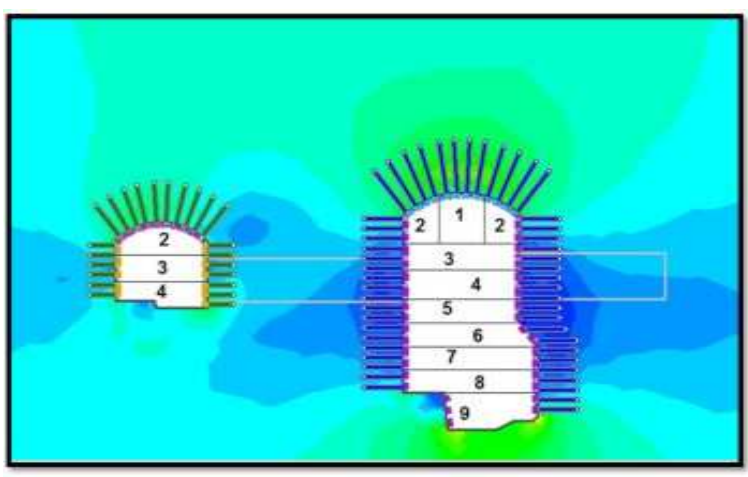

Fig. 10. The sequence of excavation in power house and transformer caverns

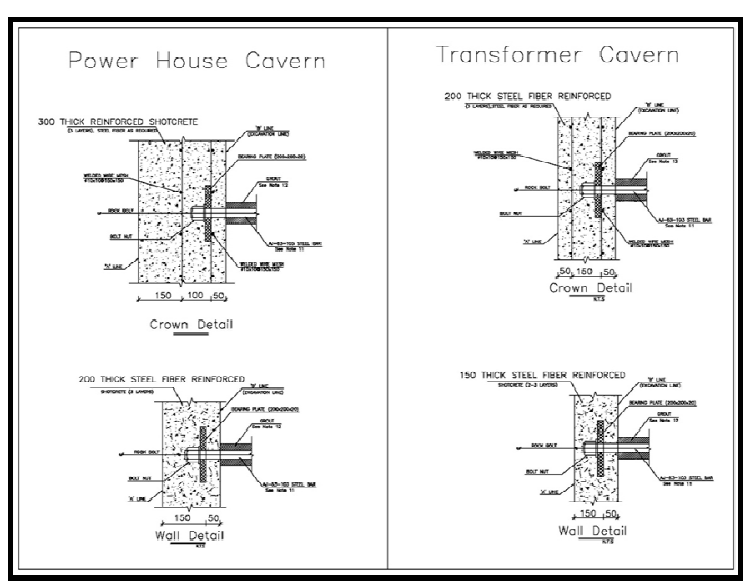

Fig. 11. The rock support details in power house and transformer caverns

Table 4. Shotceret thickness

\begin{tabular}{lll}
\hline Location & Power house & Transformer caver \\
\hline Roof & $30 \mathrm{~cm}$ & $20 \mathrm{~cm}$ \\
Walls & $20 \mathrm{~cm}$ & $15 \mathrm{~cm}$ \\
\hline
\end{tabular}

\section{General Results}

The following Table 5 give an overview on the displacements calculated with the different finite element modeling approaches. The values state that no significant displacements take place considering the size and the overburden of the caverns:

- In the elastic analysis the strength factor obtained 0.95 to 1.8. If strength factor is less than one it is assumed that the rock mass will fail in actual case
- It is been conclude that plastic zones is extend to the wall having length of above $10 \mathrm{~m}$ and to a maximum depth which can reach to $3.3 \mathrm{~m}$ in the roof, according to Fig. 12

- It must consider that after rock bolting, there are still tensile zones in the significant size of walls. Also, tensile zones are calculated in the walls and roof of cavern $5 \mathrm{~m}$ of $2 \mathrm{~m}$ deep, respectively (Fig. 13)

- According to $18 \mathrm{~m}$ span, a natural roof arch (0.144D) was calculated approximately $2.6 \mathrm{~m}$ (Huang et al., 2002). The favorable in situ stress and as well as good quality of rock and also the arch shape of the roof can create thick uniform stress zone surrounding the surface of roof

- The stress zone that transfer the loads up from the crown down to the springing and even lower to the sidewalls will show the action of roof arch

- The importance of this matter is that the roof will be self-supported rock structure. A natural selfsupported roof arch already be mobilized after systematic rock bolting, so the roof arch is stable (Fig. 14). Arching area is which area that principal stress trajectories are not horizontal or vertical except at the center lines. The thickness of arching are calculated 4.8 to 5.5 for power house and 1.6 to $1.7 \mathrm{~m}$ for transformer cavern, via FEM analysis

- The high thickness of self-supported roof arch is available because of $\mathrm{K}_{0}>1$. A research by which Huang et al. (2002), shows the higher the $\mathrm{k}_{0}$ value, the thicker the arch

- As it has been shown in Fig. 14, stress cone in transformer cavern in wider, because of power house excavation influence. Stress cone is area which principal stress trajectories are horizontal and vertical only (Huang et al., 2002)

- The additional systematic tensioned cable bolts in roof may not be rational. In case of need during construction, the mechanism of coupling deformation in walls (increasing), irregular stress concentration/distribution and high tension forces to the rock blocks nearby must be considered

- Further results indicate that changes were taken place in roof while benching due to the mobilized load in the rock bolts in the crown area and walls are low and limited to range of $4 \mathrm{~m}$ from the surface of roof, hence the strength of the rock bolts would not be totally build up

- The length of rock bolt should be proper to mobilize the maximum shear stress that resist against wedge block weight with reasonable anchorage length. In this case minimum $3 \mathrm{~m}$ anchored length is necessary

- High value of horizontal stress might cause $(\mathrm{k}=$ 1.08 ) buckling effect in walls. This phenomenon can control by short height excavation stages

- Direction of cavern is $30^{\circ}$ to maximum horizontal stress which may cause local tension saplings, but global shear failure in not expected 


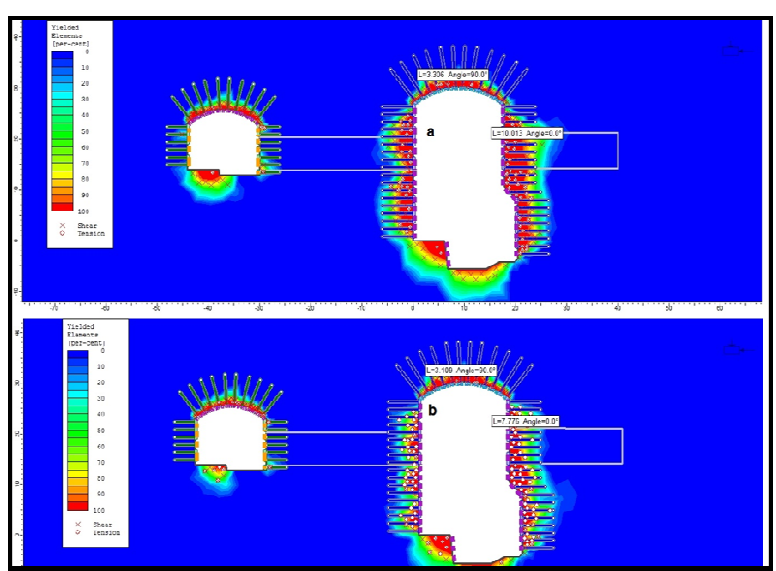

Fig. 12. Plastic zones extension, (a) Hoek- Brown, (b) MohrCoulomb

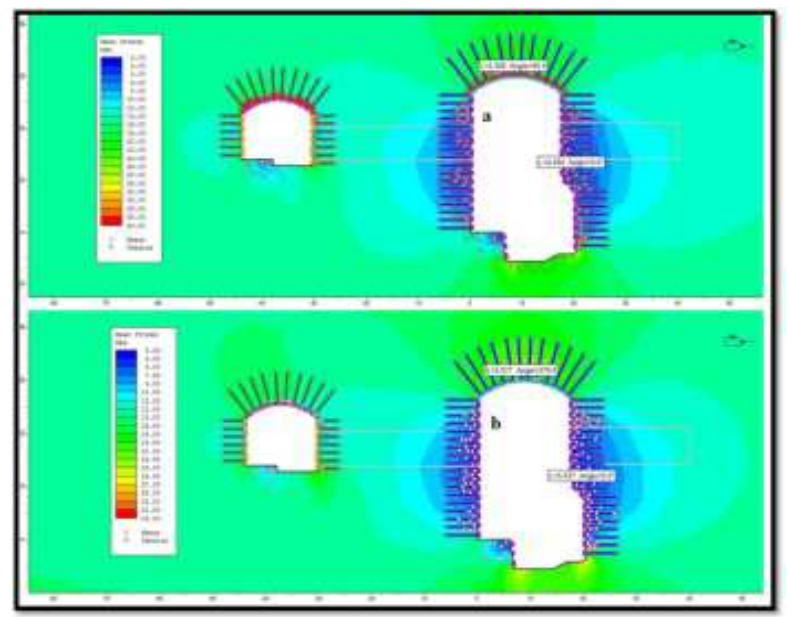

Fig. 13. Tensile zones extension, (a) Hoek- Brown, (b) MohrCoulomb

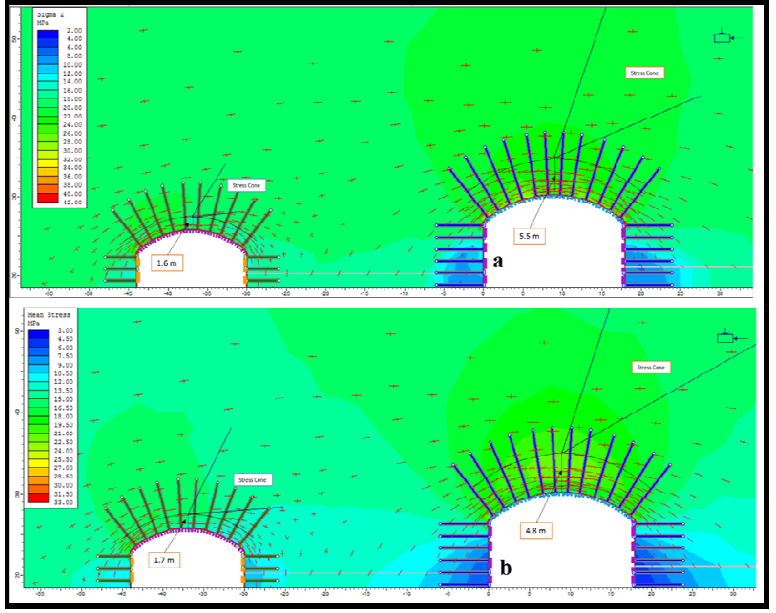

Fig. 14. Arching effect and stress cone pattern, (a) HoekBrown, (b) Mohr-Coulomb
Table 5. Displacement from finite element calculations

\begin{tabular}{lll}
\hline Criteria & $\begin{array}{l}\text { Max. displacement } \\
\text { in power } \\
\text { house cavern }\end{array}$ & $\begin{array}{l}\text { Max. displacement } \\
\text { in transformer } \\
\text { cavern }\end{array}$ \\
\hline Liner Elastic & $3.4 \mathrm{~cm}$ & $1.8 \mathrm{~cm}$ \\
Hoek-Brown & $4.5 \mathrm{~cm}$ & $3.3 \mathrm{~cm}$ \\
Mohr-Coulomb & $5.1 \mathrm{~cm}$ & $2.1 \mathrm{~cm}$ \\
\hline
\end{tabular}

\section{Conclusion}

In these paper 4 basic factors for cavern design under high stress situation discussed. Stress relaxation or deformation control in cavern rational support type should be chosen. Self-support effects can have precious impact in design and construction stage.

In Uma Oya project, the global strength of pillar is assessed 20 to $35 \mathrm{Mpa}$ and the horizontal maximum stress on the pillar walls computed 49 Mpa. Because of close range in stress and global strength, brittle breakage is conceivable. Immediate support installing in walls can avoid it.

The length of rock bolt should be long enough to mobilize the maximum shear stress that may develop. An adequate anchorage length will prevent tensile stress and also sliding through the rock joints interface in the roof.

The preference is given to short and closely spaced fully grouted rock bolts in the jointed and high stressed hard rock in comparing to the tensioned cables. When there is a need to suspend large rock wedges or blocks locally, tensioned cables can be used.

Because of $30^{\circ}$ cavern axis orientation to the high value of maximum horizontal stress, buckling deflection might happen in walls. Tensional spallling should be expected in order to stress relaxation and deformation control.

With a specific range of in-situ horizontal stress, sensible natural rock cavern roof arch and good quality of the rock can be mobilized around the roof by the excavation. The stability of the structure will be primarily retained by its geometry.

The location and thickness of the roof arch can be defined and verified by visualization of the stress field in numerical modeling. The effect of cavern shape and its crown radius should be investigated in other research.

It is evidence that after finished the excavation in site, the actual data obtained from monitoring, will help to validate the results of this article and must be considered in further research.

\section{Acknowledgement}

The author would like to thanks Mr. Mirzapour and Mr. Mehinrad for the help and advice during this work.

\section{Funding Information}

There is no external funding in this study. 


\section{Ethics}

Ethical approval was not required for this study.

\section{References}

Barton, N.R., R. Lien and J. Lunde, 1974. Engineering classification of rock masses for the design of tunnel support. Rock Mechan., 6: 189-236. DOI: $10.1007 / \mathrm{BF} 01239496$

Berthelsen, J., 1992. Guide to cavern engineering, Geotechnical engineering office-civil engineering department-The government of the Hong KongSpecial administrative region.

Bieniawski, Z.T., 1974. Geomechanics classification of rock masses proc. Denver, 11:27-32.

Cai, M., P.K. Kaiser, Y. Tasaka and M. Minami, 2007. Determination of residual strength parameters of jointed rock masses using the GSI system. Int. J. Rock Mechan. Min. Sci., 44: 247-265. DOI: 10.1016/j.ijrmms.2006.07.005

Cording, E.J., A.J. Hendron and D.V. Deere, 1971. Rock engineering for underground caverns. Proceeding of the Symposium on Underground Rock Chambers, (URC' 71), Pheonix, ASCE, pp: 407-486.

Croney, P., T.F. Legge and A. Dhalla, 1978. Location of Block Release Mechanisms in Tunnels from Geological Data and the Design of Associated Support. In: Computer Methods in Tunnel Design, Institution of Civil Engineers (Ed.), Institution of Civil Engineers, London, pp: 97-119.

Franklin, J.A. and O. Hungr, 1978. Rock stresses in Canada their relevance to engineering projects. Rock Mech. Suppl., 6: 25-46. DOI: $10.1007 / 978-3-7091-4160-13$

Grimstad, E. and N. Barton, 1993. Updating the Q-system for NMT. Proceedings of the International Symposium on Sprayed Concrete-Modern use of Wet Mix Sprayed Concrete for Underground Support, (CUS' 93), Fagernes, pp: 46-66.

Hanssen, T.H. and A. Myrvang, 1986. Rock stresses and rock stress effects in the Kobbelv area, Northern Norway. Proceedings of the International Symposium on Rock Stress and Rock Stress Measurements, Aug. 31-Sept. 3, Stockholm, Stockholm, Sweden, pp: 625-634.
Hoek, E., 2006. Practical Rock Engineering. In: Design of Large Underground Caverns-A Case History Based on the Mingtan Pumped Storage Project in Taiwan, pp: 8-10.

Hoek, E. and E.T. Brown, 1980. Underground Excavations in Rock. 1st Edn., Institution of Mining and Metallurgy, London, ISBN-10: 0900488557, pp: 527.

Hoek, E., P.K. Kaiser and W.F. Bawden, 2000. Support of Underground Excavations in Hard Rock. 1st Edn., CRC Press, ISBN-10: 9054101865, pp: 300.

Hoek, E. and E.T. Brown, 1997. Practical estimates of rock mass strength. Int. J. Rock Mechan. Min. Sci., 34: 1165-1186. DOI: 10.1016/S1365-1609(97)80069-X

Huang, Z., E. Broch and M. Lu, 2002. Cavern roof stability - Mechanism of arching and stabilization by rockbolting. Tunnell. Underground Space Technol., 17: 249-261. DOI: 10.1016/S0886-7798(02)00010-X

Ladanyi, B., 1974. Use of the long term strength concept in the determination of ground pressure on tunnel linings. Proceedings of the 3rd International Congress on Rock Mechanics, (CRM' 74), Denver, pp: 1150-1156.

Lee, C.F., 1978. Stress induced instability in underground excavations. Proceedings of the 19th US Symposium Rock Mech. Reno, (RMR' 78), Univ. of Nevada Publ., pp: 165-173.

Panthi, K.K., 2006. Analysis of engineering geological uncertainties related to tunnelling in Himalayan rock mass conditions. PhD Thesis, Norwegian University of Science and Technology.

Rabcewicz, L.V., 1964; 1965. The new Austrian tunneling method. Water Power, 16: 453-457.

Selmer-Olsen, R. and E. Broch, 1977. General Design Procedure for Underground Openings in Norway. Storage in Excavated Caverns, Bergman, S. (Ed.), Pergamon Press, Elmsford, pp: 219-226. 